Atonalismo y dodecafonismo en la gran pantalla: sus usos dentro del medio cinematográfico a partir de la película The Mephisto Waltz (1971)

\author{
Atonalism and Twelve-tone Music in the Big Screen: \\ its Uses in Cinema from The Mephisto Waltz (1971)
}

Ruymán Martín Quintanal

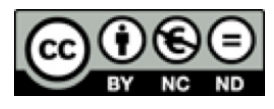

Esta obra está bajo una licencia Creative Commons Reconocimiento-No comercial-Sin Obra Derivada 


\title{
Atonalismo y dodecafonismo en la gran pantalla: sus usos dentro del medio cinematográfico a partir de la película The Mephisto Waltz (1971) ${ }^{1}$
}

\author{
Atonalism and Twelve-tone Music in the Big Screen: \\ its Uses in Cinema from The Mephisto Waltz (1971)
}

\author{
Ruymán Martín Quintanal ${ }^{2}$ \\ Universidad Politécnica de Valencia \\ España
}

Recibido: 23 de agosto del 2017 Aprobado: 17 de octubre del 2017

\begin{abstract}
Resumen
En esta investigación analizamos el uso de la música atonal y dodecafónica en el cine con relación a los discursos estéticos surgidos en el origen de sendas estrategias compositivas. El objetivo es realizar un planteamiento sobre la relación del aspecto musical y visual que se produce en el proceso fílmico y mostrar de qué manera se utiliza la estética de la música de la Escuela de Viena según las necesidades del producto cinematográfico.
\end{abstract}

Palabras clave: música cinematográfica; atonalismo; dodecafonismo; cliché; Escuela de Viena

\begin{abstract}
In this research we analyze the use atonal and twelve-tone music in cinema in relation to the current aesthetics that emerged at the origin of both compositional techniques. Our purpose is to make an approach on the relationship between music and image on cinema. Likewise, we want to study the way in which the musical aesthetics Second Viennese School is used according to the needs of the cinematographic product.
\end{abstract}

Keywords: Film music; Atonalism; Twelve-tone music; Cliché; Viennese School

1 Este artículo se desprende de la Tesis de fin de Máster del autor Atonalismo en el cine: origen estético y usos

2 Doctorando en Arte: producción e investigación en la Universidad Politécnica de Valencia. Máster en Música por la misma institución. Correo electrónico: ruymarqu@posgrado.upv.es 


\section{Introducción}

Los lenguajes compositivos que emplearon Schönberg y algunos de sus discípulos durante el periodo de la Escuela de Viena se han revelado como medios muy versátiles dentro del mundo cinematográfico. Compositores como Jerry Goldsmith, Aaron Copland y Miklós Rózsa, entre otros, han escogido estos recursos a la hora de componer las bandas sonoras de algunos de sus filmes. La música atonal y dodecafónica se ha usado, escasamente, en cine, pero, si sometemos a análisis los largometrajes de los que disponemos actualmente puede comprobarse las posibilidades de adaptación de las bandas sonoras a la parte visual de las películas. Es decir, la manera en que la parte musical se adapta a la imagen es muy funcional debido a su naturaleza formal, basada en estructuras cortas, que resultan más flexibles que el sinfonismo romántico que abunda en la mayor parte de las producciones.

A partir de la segunda mitad del siglo XX, los directores aprovecharon el desfase temporal producido con respecto a la etapa de la composición atonal y dodecafónica de los años 1910 a 1920 para readaptar sus usos. La reconciliación entre la vanguardia musical vienesa de la primera mitad del siglo XX y el público fue posible gracias a la coordinación de música e imagen en el cine. Este medio de masas ha sido capaz de acercar a los espectadores del audiovisual a dos vías compositivas tan complejas como el atonalismo y el dodecafonismo. Ambas se utilizan, con frecuencia, a modo de cliché en el cine de terror, debido, fundamentalmente, a la readaptación de los usos desde su creación y anterior función como música autónoma y, especialmente, programática dentro de la ópera.

\section{El papel de la música atonal en el cine}

El atonalismo en el cine tiene una influencia muy limitada, está, prácticamente, reducida al cine de terror de la segunda mitad del siglo XX. Si bien su presencia en las películas es escasa, su función dentro de la banda sonora aporta connotaciones muy claras y tiene una adaptabilidad sin precedentes. La mayoría de los investigadores que comentan positivamente las características principales del uso del lenguaje atonal y el dodecafonismo en el cine aducen que son adecuados para estructurar las películas por su forma y ritmo flexibles. Así, establecen comparaciones con el neosinfonismo de la década de 1950 de procedencias románticas, que al tener relación con la música autónoma y debido a su estructura y ritmo tan cerrados no encaja con la misma eficacia.

Theodor Adorno y Hans Eisler (2005) recuerdan que lo característico de la música culta de los siglos XVIII y XIX es la forma y, que a partir del siglo XX se tiende a la irregularidad formal que resulta más conveniente para el cine. Lack (1999) propone una idea similar al comentar la llegada de la disonancia y los nuevos lenguajes, los que al suprimir el aspecto 
Atonalismo y dodecafonismo en la gran pantalla: sus usos dentro del medio cinematográfico... Artículos

estático del sonido eliminan, también, la sensación de resolución, ello encaja con lo inestable de las tramas y el manejo de tensiones en las películas. Además, comenta sobre el tema de la forma y la estructura, que los pasajes atonales aportan al cine la posibilidad de estructurar y enfocar la acción dramática musicalmente, muy lejos de las estrictas divisiones formales, propias de la música tonal, que son un desafío para la distribución de los tiempos en las producciones cinematográficas. Sobre esto también habla Gilles Mouëllic (2011), quien sostiene que en la escucha de música atonal ocurren una serie de sucesos en relación con el oyente (se pierden los puntos de referencia, se rompe la sensación de temporalidad, la música resulta poco predecible, entre otros), de forma que no es capaz de intuir las fluctuaciones de la tensión generada. Esto explica la sensación de misterio y suspensión temporal en algunos filmes con música atonal. Nöel Burch (1973 citado por Lack, 1999, p. 101) en su texto Theory of film practice propone el atonalismo y el serialismo como músicas que actúan en beneficio del filme, alude, de nuevo, a las libertades rítmicas, tanto de la música como del cine, y destacan que mediante su uso todos los elementos que intervienen en la composición cinematográfica adquieren el mismo valor.

Existe un desfase temporal entre la música que compusieron tanto Schönberg, como sus discípulos y la música que se emplea en las películas posteriores a la escuela de Viena, lo que supone, para el compositor de cine, la opción de manejar una técnica compositiva poco conocida en las últimas décadas para condicionar su naturaleza al utilizarla como música programática en el filme, cuestión que más adelante comentaremos. En cuanto a los compositores pioneros en atonalismo y dodecafonismo en Europa, ha sido ampliamente comentada la efímera relación de Schönberg con la composición cinematográfica, que también describiremos en referencia a los significados de las estéticas generadas en la escuela de Viena. Schönberg compuso la ópera Die glückliche hand en la época de los primeros largometrajes con sonido (1924) y es probable que, si la producción de la versión fílmica se hubiese llevado a cabo habría constituido una obra de música absoluta (Lack, 1999). De esta afirmación, se extrae que la mentalidad compositiva con la que estaba planteado era cercana a la de Wagner en el drama. Sin embargo, la realidad actual, como propone María de Arcos (2006), es diferente al ser el concepto de gesantkumstwe ${ }^{3}$ prácticamente imposible de realizar, ya que la evolución cinematográfica ha concedido un mayor protagonismo a lo visual en comparación con lo sonoro.

${ }^{3}$ La obra de arte total que propugnaba Wagner. Una obra integrada por música, teatro y aspectos visuales con una valoración ecuánime entre todos ellos

ESCENA. Revista de las artes, 2018, Vol. 78, Núm. 1 (julio-diciembre), pp. 27-45. ISSN 2215-4906 
Mediante el empleo de la música del siglo XX en el cine y, especialmente, en lo concerniente a las técnicas compositivas derivadas del atonalismo, podemos comprobar cómo se ha creado, en el transcurso histórico, un sistema de códigos de comunicación audiovisual según los cuales, el público es capaz de comprender ciertas informaciones que la música aporta. Este suceso acaba normalizándose y convirtiéndose en un tema cultural. En nuestro estudio documentamos y analizamos la formación y el funcionamiento de estos códigos cinematográficos.

\section{La ruptura comunicativa en el cine}

Nos centraremos ahora en el panorama general de la música erudita del siglo XX y en el atonalismo y dodecafonismo en particular. Propondremos los usos en la banda sonora como creaciones auxiliares del cine que, en algunos casos, pierden su función como música autónoma al complementarse con la imagen y, en otros, cambian la forma de adecuarse a la realidad a la que acompañan como música programática. Una película es un proyecto en el que intervienen múltiples cuestiones: escenografía, fotografía, vestuario, entre otros. Todos estos factores suelen ser asumidos por el público como el trabajo de un único autor (el director de cine). Si bien la música es una de las cuestiones que intervienen en la producción fílmica, puede afirmarse que, como parte del todo en el que está integrada, rompe -especialmente en el caso de la música autónoma- con su natural incitación a la reflexión estética y a la comunicación. En la música autónoma la comprensión de valores culturales inmanentes a la misma es esencial para la emoción y, especialmente, en el caso de la música atonal, ya que su deriva armónica, melódica y rítmica resulta impredecible para el auditor, factor que dificulta la comprensión de ciertas asociaciones culturales presentes en su lenguaje.

Por lo anterior, decimos que se crea una ruptura comunicativa entre compositor y público, debido a que los consumidores de cine ya no son meros auditores, sino consumidores de todos los elementos que integran el producto audiovisual. Además, el cine comparte con la música, tanto el hecho de ser un arte temporal, como su naturaleza abstracta; al igual que las obras musicales, las películas tienen significados explícitos y cerrados en su contenido principal, pero, a un nivel crítico pueden percibirse ideas más abiertas que conceden al espectador la posibilidad de someterlas a la discusión. Sin embargo, el cine no es el origen de esta ruptura; el problema tiene su raíz en la música autónoma de comienzos del siglo $X X$, particularmente, en la Escuela de Viena, donde se acentuó la distancia entre creador y consumidor en la música culta. Alejandro Román se refiere a Darmstat como principal núcleo de conflicto, señalando que:

en toda expresión artística innovadora con vocación e intención comunicativa no pueden perderse nunca ciertos elementos comunes que pertenecen tanto al bagaje cultural del emisor como del receptor, algo que fue norma habitual en las corrientes más vanguardistas del pasado siglo XX, Darmstat y el serialismo integral, lo cual ha provocado una ruptura 
Atonalismo y dodecafonismo en la gran pantalla: sus usos dentro del medio cinematográfico... Artículos

casi insalvable entre compositor y público. Es una ruptura que aún padecemos, dados determinados pensamientos absolutistas basados en la negación más rotunda del valor de la comunicación musical (2008, p. 104).

En este tema también hay cierta discordia, por ejemplo Lack (1999) comenta que la música atonal no ha sido tan usada como otras en el cine. Por un lado, eventualmente, por el temor a la consecuencia más presumible, que sería, en este caso, el distanciamiento de la mayor parte de los espectadores con respecto al medio cinematográfico. Además, es probable que el compositor se negase a seguir un camino diferente a la herencia del dramatismo y emoción que, normalmente, garantizaba el éxito del producto fílmico. Por otro lado, afirma que la música contemporánea es aceptada con menor dificultad en el cine que en las salas de conciertos por el hecho de ir ligada a la imagen. Gracias a su estructura armónica aporta la sensación de algo inacabado que puede resultar lícito en el filme, pero en los conciertos, la suerte es diferente con respecto a los oyentes.

A pesar de que la ruptura comunicativa en cine puede deberse tanto al compositor como al público, también interviene la propia música. Román (2008) habla de dos tipos de asociaciones. Por un lado, las naturales, que serían el tempo, la altura y el timbre, por otro, las culturales, entre las que estarían las cadencias, la armonía, el cromatismo, entre otras. De ello se extrae que la música atonal y dodecafónica produzca en el oyente sensaciones chocantes. Chion (1997) propone que el compositor, en la mayoría de las películas, es poco conocido y no se le concede mérito a su creación. Son, incluso, menos conocidos por causa de sus migraciones, ya que al trabajar en otros países no son apreciados en sus naciones de origen.

Como explica Jesús Alcalde (2007b) a diferencia de lo que sucede en el cine más popular del siglo XX, en la música autónoma los compositores querían eliminar la impronta romántica de la composición formada por secciones y utilizar otras posibilidades más allá del sinfonismo procedente del siglo XIX, que se consideraba agotado. Alcalde alude al carácter comunicativo de la música como algo lejano a los compositores del siglo XX, ya que se evitaba la inserción de la música en todo lo comercial, sin pretensiones de popularidad por parte de los creadores:

A partir de este enfoque no podemos decir que la música del siglo XX sea realmente no comunicativa. No lo es en cuanto que el compositor no pretende transmitir sentimientos propios ni mover los afectos del público, como una representación de algo que está ahí, ni pretende valerse de un vocabulario y una gramática conocidos. Para el músico de la vanguardia no son solo las emociones el objeto de comunicación, también lo son las propuestas de una nueva percepción. Comunicar es también enseñar a percibir. Hacer

ESCENA. Revista de las artes, 2018, Vol. 78, Núm. 1 (julio-diciembre), pp. 27-45. ISSN 2215-4906 
música es también hacer un discurso sobre la música. No interesa la música como algo transitivo, ni la emoción como el objeto de un lenguaje de sonidos; el centro de atención es el propio sonido (2007b, p. 181).

Fernando López Graça (citado por Laborada, 2004, p. 155) define un estado de la composición musical muy concreto, parte de la creación musical portuguesa del siglo XX y propone la idea de que el compositor y el público no se relacionaban, moviéndose el compositor entre su diminuto círculo formado por músicos que tenían una visión conjunta de la composición, sin dirigirse ninguno hacia los mismos fines estéticos. Esta definición encaja de lleno con la exclusividad que caracterizaba a los compositores de la escuela de Schönberg. María de Arcos (2006) expone que en la sociedad privada de audiciones musicales, que se creó en la Escuela de Viena, el aforo estaba reservado a auditores muy selectos, con amplios conocimientos musicales, lo que se convirtió en una austeridad tan profunda que no se daban aplausos entre las interpretaciones musicales.

Es conveniente centrar la atención en los espectadores y la crítica cinematográfica, ya que de su criterio depende la valoración general del producto cinematográfico. Si se diera más importancia al uso de la música en cine desde una perspectiva crítica -especialmente cuando la banda sonora contiene técnicas o estrategias compositivas poco comunes-, probablemente, se generarían posturas más abiertas a una cierta variedad de usos musicales en el cine, ya que la comprensión es la que consigue desencadenar un cierto interés, tanto en este caso, como en el de la música autónoma. Otro de los factores de separación de compositor y público puede ser el juicio establecido por parte del público de que la música dodecafónica es muy compleja, con lo que puede argumentarse el rechazo inmediato que recibió en sus inicios. Tomás Marco muestra una visión contraria:

Es rigurosamente verdadero que la técnica dodecafónica no es ni más ni menos compleja ni de mayor o menor contenido matemático traducido a música que el sistema armónico tonal funcional. Sin embargo, es cierto que el dodecafonismo ha tenido siempre un cierto tufillo esotérico para los no iniciados y una apariencia criptológica (2002, p. 182).

María de Arcos (2006) analiza la existencia de "una tendencia generalizada en la música contemporánea a intelectualizar su proceso compositivo, de manera que se juzga a veces la obra musical como fruto de una excesiva especulación" (p. 93). Esto que comenta ha conducido al público a la incomprensión y, en consecuencia, al rechazo. Sin embargo, comenta que "el empleo de estos medios no trata, en realidad, de racionalizar la escucha, sino de obtener un resultado paradójicamente abstracto y expresivo" (p. 93). Respecto al 
Atonalismo y dodecafonismo en la gran pantalla: sus usos dentro del medio cinematográfico... Artículos

cine señala que en el uso de la música contemporánea hay una expresividad poco definida y una falta de asociación de la música con sensaciones concretas en la codificación de significados, pudiéndose extrapolar esto al ámbito de la música atonal. Asimismo, comenta:

A tenor de las características expuestas (amelodismo, atematismo, ausencia de direccionalidad), el oyente, habituado a realizar asociaciones de tipo expresivo durante la audición musical se halla bloqueado. Incluso el título de la obra elemento muy orientador deja de poseer la acostumbrada codificación semántica con respecto a la música, durante largos años tácticamente aprobada: por ejemplo, la pieza número 4 de las seis piezas para orquesta Óp. 6 de Anton Webern se denomina Marcha fúnebre, a pesar de lo cual no ostenta un carácter lúgubre, melancólico o triste (De Arcos, 2006, p. 91).

Marco (2002) denuncia, desde el ámbito teórico y del conocimiento de la composición musical, la mala gestión cultural con respecto a la música contemporánea, indicando que, por lo general, estamos comenzando a darnos cuenta poco a poco de la insuficiente difusión y uso del arte contemporáneo en la sociedad actual. Un problema cuya responsabilidad recae en las deficiencias de los hábitos comunicativos de la era posmoderna. Por tanto, la no aceptación de ciertas categorías del arte es un reflejo de una actualidad en la que se ha generado sobre el mismo una escasa valoración como vehículo de comunicación.

Si algo resulta a todas luces coherente con la función principal del arte, en este tema, está en la parte que corresponde a los usos de la música en el filme. La ruptura comunicativa de la que hablamos es, después de todo, una ruptura parcial, porque respecto a los significados, en producto, genera nuevas formas de comprensión comunicativa. En este caso, la música comunica ciertas ideas formando una alianza con la imagen, a la cual reviste de un relieve simbólico. De hecho, la maestría de una producción cinematográfica, cuya estética musical resulta poco conocida para el público, es generar nuevos significados y conseguir que hagan mella en la conciencia colectiva.

\section{Análisis del uso de la música en The Mephisto waltz (1971)}

En la película The Mephisto waltz (1971), Myles es un joven pianista que ha abandonado sus esperanzas de tener una carrera profesional como instrumentista y comienza a trabajar como periodista musical. Cuando entrevista a Duncan Ely, uno de los mejores pianistas del momento, el viejo instrumentista se fija en sus manos, que parecen perfectas para tocar el piano. A Paula, la mujer de Myles, le transmiten malas vibraciones Duncan y su hija Roxanne, pero Myles se hace amigo del viejo pianista, que es en realidad un adorador de Satán que consigue hacer un ritual por el cual, al morir, su alma transmigraría al cuerpo joven del periodista. Tras ello, Myles se convierte en un virtuoso pianista con una personalidad fuerte que agrada a Paula, aunque también le resulta inquietante. Paula comienza a 
tener pesadillas y sueña con la muerte de su hija Abby a manos de Myles, quien al conocer el sueño de su mujer le comenta que la niña era parte del trato con Satán. Al morir su hija, Paula investiga a Roxanne y conoce a su exmarido Bill, con el que tiene una aventura amorosa. Sin embargo, este muere en un accidente al poco tiempo de comenzar a intimar con Paula, quien sospechó que el accidente fue provocado por Duncan y Roxanne, por lo que sospecha que la siguiente en morir sería ella. Paula, por amor al alma de Duncan en el cuerpo de Myles, se convierte al satanismo y hace un ritual por el que su alma pasa al cuerpo de Roxanne. Así, deja en la bañera su cadáver con heridas que simulaban un suicidio. En el cuerpo de Roxanne, Paula vuelve a casa para encontrarse con Duncan en el cuerpo de Myles. Ella le habla de su supuesto suicidio, y comienza, así, una relación, incestuosa para Duncan, quien no sabe que el cuerpo de su hija lo habita otra alma.

Para realizar el análisis, estudiamos los usos de la música dodecafónica y los leitmotive en los personajes principales, con el minutaje y la descripción de los acontecimientos de las escenas y secuencias de la película en las que la Banda Sonora contribuye a crear distintos tipos de significados. De esta manera, se mostrará la forma en que las apariciones de la música, en determinados momentos de la película, genera significados que acompañan y definen aspectos representativos de la imagen o de circunstancias ajenas a la misma. Respecto a la posibilidad de un análisis con ejemplos en pentagrama, es necesario aclarar que no existen ejemplares disponibles de la partitura original de la Banda Sonora, por lo que no podemos mostrar en imágenes las partes de música atonal y dodecafónica que acompañan a las melodías líricas de la obra de Liszt. Pero sí se mostrarán las imágenes de las melodías del Mephisto waltz empleadas para fundamentar los dos leitmotive principales de la película: el fondo de piano de la escena en la que Duncan resucita en el cuerpo de Myles.

\section{Análisis de los usos musicales}

En el minuto 18: 40, poco después de la fiesta en casa de Duncan, en la cual se utiliza música diegética, comienzan a aparecer motivos atonales como elementos narrativos. Es una fiesta de libertinaje, en la que los invitados consumen drogas y llevan la cara cubierta por máscaras y maquillaje. Durante el minuto 21: 24, cuando Paula sube al piso superior de la casa, se oyen motivos dodecafónicos en los violines con vibrato. Se trata de una escena oscura y nocturna, en la que Paula ve una serie de moldes de caras humanas y objetos que la inquietan. Aparece el perro de Duncan, un animal rabioso. Paula lo percibe como un presagio del mal. En el momento en el que aparece Roxanne y lo calma reaparece la música diegética de la fiesta. 
Atonalismo y dodecafonismo en la gran pantalla: sus usos dentro del medio cinematográfico... Artículos

Seguidamente, en el minuto 30: 35, de nuevo, se escucha música dodecafónica con vibrato en los violines cuando Duncan está a punto de morir y Roxanne se despide de Myles, consciente de que su alma va a ser reemplazada por la de su padre. El ritual satánico se realiza en un ambiente oscuro, tenebroso y nocturno. Inmediatamente después, cuando Roxanne vuelve a la sala donde reposa Myles y coge un bote de tinta azul para usarla como ingrediente en el ritual, se percibe la presencia del ruidismo en la música, que parece simbolizar una presencia maligna. Durante el minuto 31: 50 Roxanne dibuja un punto de tinta azul en la frente de Myles y suena una variación rítmica de las quintas superpuestas del Mephisto waltz de Liszt en los violines. Acto seguido se escucha música atonal. Los violines tienen menos presencia, se adaptan a las palabras que recita Duncan para rendir culto a Satán antes de viajar al cuerpo de Myles.

Figura 1. Leitmotiv de quintas

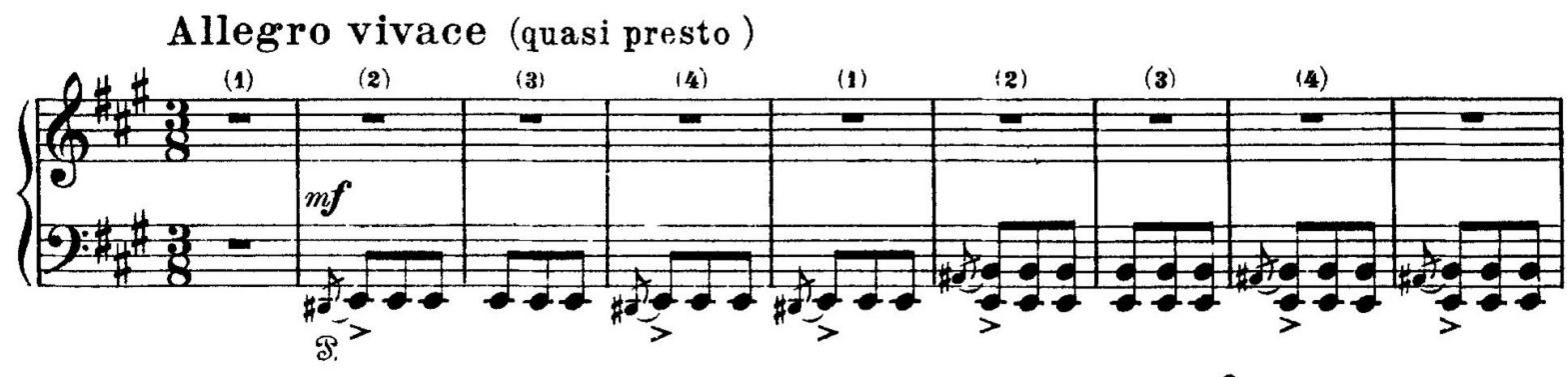

Fuente: Mephisto waltz No.1 de Liszt.

En el minuto 33: 48, el sonido de la campanada es un símbolo de la muerte. Para acelerar la defunción de Duncan, Roxanne le introduce una especie de veneno. Después, en el minuto 35: 45 se escuchan pasajes del Mephisto waltz de fondo con efectos de eco en la música. El joven se levanta y acto seguido se desvanece, fruto de la transmigración del alma de Duncan, quien aparece encarnado, mientras suena la música de piano romántico en esta escena. En el minuto 36: 28 suena la parte final del Mephisto waltz (Più mosso), en tonalidad mayor. Así, se constituye una nueva sección de la obra, la cual transmite la sensación de un nuevo comienzo, cuando el alma de Duncan está despertando en el cuerpo del joven. Debido a ello, este es el único momento del filme en el que se usa este pasaje de la obra. 
Figura 2. Fragmento del pasaje Più mosso

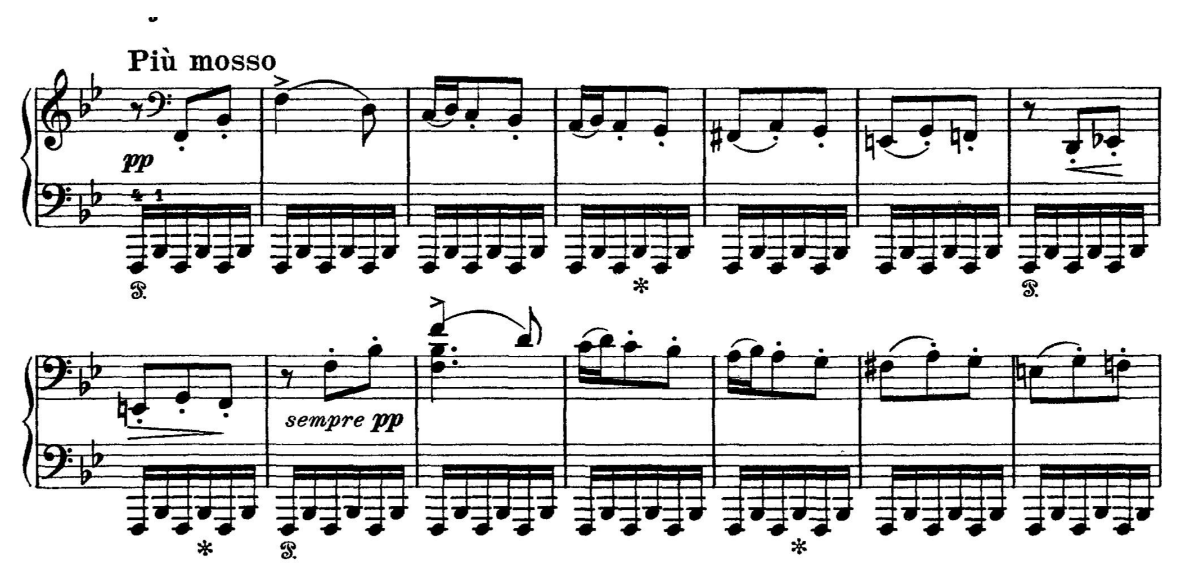

Fuente: Mephisto waltz No.1 de Liszt.

En el funeral de Duncan (minuto 40: 32), se mezcla lo tonal con lo atonal y se reintroducen las quintas del Mephisto waltz, que aparecen mientras llevan el difunto cuerpo del adorador de Satán metido en su féretro. Goldsmith alarga el motivo de las quintas en el minuto 42: 00, al trasponer los intervalos a un registro más agudo y añadir sextas menores (muy similar al empleo de estos intervalos en Liszt). Puede apreciarse como en los momentos de normalidad y exaltación emocional (normalmente en escenas de sexo) aparece música romántica. A la vez que, cuando se hace alusión a Satán o a la oscuridad aparecen las técnicas atonales acompañando a los leitmotive principales, así como en los momentos de situaciones cotidianas, cuando Duncan está en el cuerpo de Myles.

En el minuto 45: 40, Paula le dice a Myles que antes era educado y que su personalidad ha cambiado. Él le contesta con ironía que eso sucedía cuando era pobre. Ella se tumba y mantienen relaciones sexuales. En este momento, suena el motivo del pasaje un poco meno mosso en el piano, mezclado con un fondo instrumental atonal. El sexo es mejor con Duncan y cuando comienzan a practicarlo suena un motivo del vals de Liszt con más intensidad en los violines. En esta ocasión, los sonidos que hacen de bajo implican la aparición de centros tonales. Acto seguido, la música lírica termina y pueden escucharse las quintas del comienzo del vals en los violines. 
Atonalismo y dodecafonismo en la gran pantalla: sus usos dentro del medio cinematográfico... Artículos

Figura 3. Fragmento del pasaje un poco meno mosso (come prima)

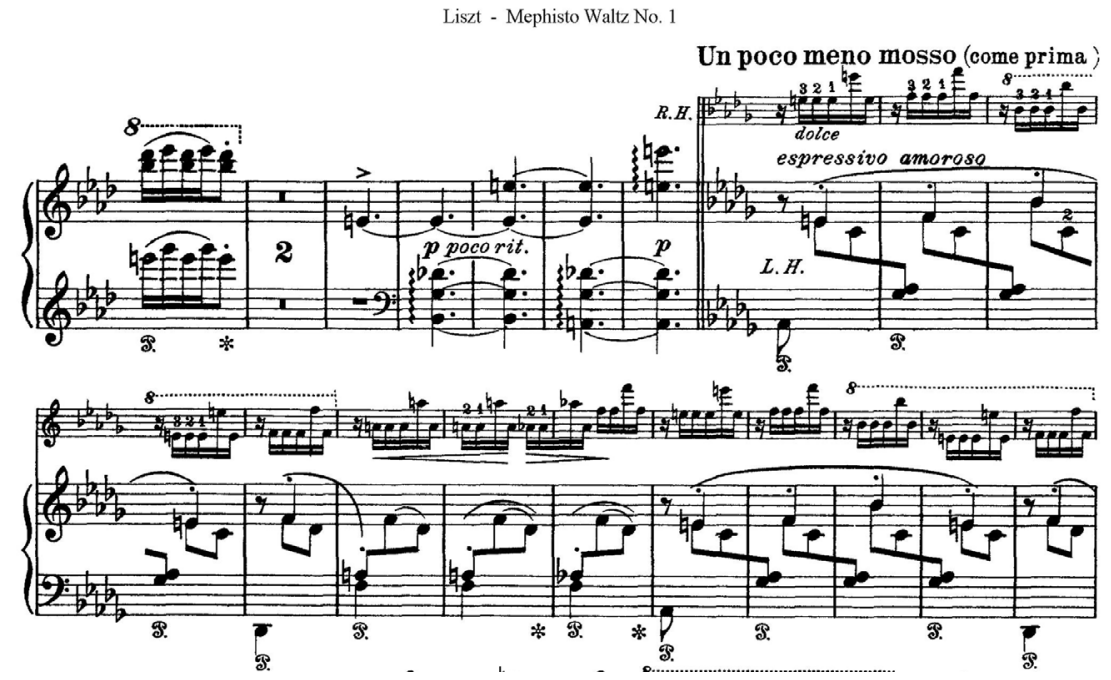

Fuente: Mephisto waltz No.1 de Liszt.

En el minuto 55: 16 Paula y Myles duermen. Suena la melodía del vals un poco mosso con sonido de campanas, mientras Paula comienza a soñar. Durante el sueño aparecen motivos dodecafónicos. Paula puede ver en su fantasía cómo el perro que vio en la fiesta mordía un muñeco encima de la alcoba. Se escuchan descensos microtonales en la cuerda. El decorado es blanco, incluido el camisón de Paula, pero es de noche y hay cierto ambiente tenebroso. El blanco implica la pureza de ella en el contexto del rito satánico. Mientras que el perro con su pelaje negro sugiere la noche, la muerte y la maldad. Aparece la figura de Duncan con un traje negro y suenan las quintas del vals en los violines. Duncan es Satán en un cuerpo humano envejecido y experimentado, le dice que va a ir a donde está su hija, que no quiere herirla, pero tiene que hacerlo; le habla del pacto satánico.

La música dodecafónica suena de nuevo, en el minuto 57: 20, cuando Duncan entra en el cuarto y pinta el punto azul en la frente de su hija, Abby, mientras ella llama a su madre en sueños. La música acumula toda la tensión dramática cuando Duncan pone el punto en la frente de la niña. Se aporta énfasis en las partes tensas de la historia mediante la intensidad y las relaciones interválicas de cercanía en el movimiento armónico. La simbología del color es similar a la anterior pesadilla de Paula; las sábanas y el camisón de la niña son de colores claros; Duncan lleva un traje negro. De repente, Paula despierta y se da cuenta de 
que tanto ella como su hija han tenido una pesadilla. Paula le levanta el flequillo a su hija y se percata de que tiene la marca azul. La sorpresa se ambienta con ruidos y música atonal (minuto 60: 00). Seguidamente, el doctor da el diagnóstico de la niña. Es un diagnóstico positivo, pero la música es dodecafónica. Se percibe un cierto ambiente de misterio porque, aunque la niña está bien, Paula no deja de preguntarse qué está ocurriendo. El dodecafonismo sigue presente cuando Paula entra a la sala de espera con Myles. Es, también, utilizado para ambientar la situación de misterio y desconcierto. Al minuto 61: 15, Paula dialoga con Myles sobre si los sueños cuentan la verdad. Cuando terminan de hablar, las quintas del vals unen esta escena con la siguiente en la que amanecen en el hospital esperando noticias sobre su hija. El dodecafonismo vuelve (minuto 64: 40), cuando Paula ve en el periódico la noticia de un perro negro asesinado a manos de unos ciudadanos suizos. Inmediatamente, Paula está extrayendo conclusiones mientras se dirige a investigar a Roxanne y a su exmarido. Vuelve a aparecer música atonal, esta vez, con el leitmotiv de un poco meno mosso en el piano.

A continuación, en el minuto 76: 49 aparece Bill, exmarido de Roxanne, le cuenta a Paula que Duncan mató a su hija: aparece música atonal y ruidos. Bill explica a Paula que no cree en el demonio, pero sí en la maldad de quienes tienen fe en él. Aquí comienza a hacerse notar la asociación de la música a la inocencia o a la maldad dependiendo de las situaciones, ya que Paula y Bill están hablando de la familia del segundo y no aparece el vals. Sin embargo, sí se escucha cuando Bill sale y el plano se centra en la cara de Paula, que está meditando sobre el posible cambio de alma de Duncan con su marido, después de las explicaciones que Bill le ha dado sobre el caso de su familia. El motivo del vals en el piano explicita la persona en la que está pensando Paula. En la escena siguiente ya es de día y Bill no está. La música es dodecafónica y, esta vez, no aparece el motivo del vals. Paula busca a Bill en la terraza de la casa, mientras el ambiente general es de misterio.

Al minuto 78: 35 Paula encuentra a Bill muerto sobre las rocas de la playa. La música dodecafónica sigue sonando. El joven tiene el punto azul en la frente, cuando el plano de la cámara -simulando la mirada de Paula- lo detecta surgen las quintas del vals en los violines. Puede comprobarse que las quintas son el leitmotiv de Satán y representan la huella que va dejando su ritual. Justo después, suena música dodecafónica. La música acaba con el cambio de secuencia y aparece un silencio absoluto en el momento en que Paula comienza a dar explicaciones a los policías. Cuando expone sus sospechas sobre el asesinato de Bill a manos de Duncan, los pensamientos sobre su marido y el alma del satánico, la música dodecafónica surge de nuevo y continúa escuchándose en el cambio de secuencia; esto funciona de forma estructural y semántica. De este modo, se muestra otro de los usos del dodecafonismo en la película, que implica la reflexión del personaje de Paula. 
Atonalismo y dodecafonismo en la gran pantalla: sus usos dentro del medio cinematográfico... Artículos

Más tarde, al minuto 80: 10, un taxi lleva a la joven a casa y aparece el leitmotiv de un poco meno mosso con música dodecafónica ornamentando de fondo la melodía lírica de Liszt. Entra en la casa y sigue pensando en lo ocurrido. En este momento, vuelve a sonar el último leitmotiv que se desarrolla con una armonización e instrumentación diferentes. Después, Paula sueña que Myles y Roxanne entran en su cuarto de la mano, vestidos de negro. Aquí, suenan las quintas en el piano, debido a la manifestación del alma de Duncan en el sueño de Paula. El leitmotiv en el piano aparece debido al reconocimiento de la figura de Duncan en el cuerpo de Myles, ya que Paula ha comenzado a descubrir todo lo que había ocurrido. De nuevo, la somnolienta aparece vestida de blanco en un ambiente de música atonal. Es un sueño más directo que el primero, fruto de la especulación de la joven. Su subconsciente le dice que quieren matarla después de haber asesinado a todos los demás. Paula, atemorizada por los sueños y su relación con la realidad, ve confirmarse todas sus reflexiones anteriores. Roxanne coge, una vez más, el frasco de tinta azul para ponerlo en la frente de Paula.

Posteriormente, Paula puede ver como Duncan y Roxanne comienzan a besarse. La carga romántica se corresponde con el leitmotiv de un poco meno mosso de Liszt, que ahora suena transformado en un arreglo tonal en el piano, con algunas notas añadidas a modo de ornamento. De esta manera, florece el amor satánico entre Roxanne y Duncan, al haber acabado con todos aquellos que formaban parte del pacto. El motivo tonal del vals suena en el piano y en los violines, esta vez, sin el fondo instrumental atonal. Después, se escuchan campanas - de nuevo simbolizando la muerte- cuando Paula despierta atemorizada de su pesadilla.

Tras unos segundos de música dodecafónica, en el minuto 84: 23, Paula se toca la frente y mira su mano manchada de azul. Este es el momento de mayor tensión en la película y Goldsmith recurre a dos motivos canónicos del cine. En primer lugar, se escuchan tres sonidos disonantes y chirriantes en los violines, que recuerdan a la música de la escena de la ducha en Psicosis (1960), compuesta por Bernard Herrmann. Acto seguido, cuando Paula se levanta para ir al baño a quitarse la mancha, aparecen dos notas en intervalo de medio tono que, reiteradas durante su huida, constituyen la base para la línea melódica de los demás instrumentos. Esta es interrumpida, en ocasiones, por los golpes de un idiófono similar al xilófono, que contribuyen a narrar el shock de Paula. En este caso, Goldsmith hace alusión a la música de la escena de peligro en Jaws [Tiburón] (1975), de John Williams. La música refuerza su ritmo binario para darle tensión a la música atonal. Aparecen tres notas que hacen reconocible el leitmotiv de un poco meno mosso dentro del fondo atonal, mientras la joven busca la llave del coche en el armario: quiere escapar de Duncan, cuya intención es asesinarla.

ESCENA. Revista de las artes, 2018, Vol. 78, Núm. 1 (julio-diciembre), pp. 27-45. ISSN 2215-4906 
Posteriormente (minuto 86: 10), Paula descubre el molde de Duncan y la música atonal reduce su protagonismo, así, sobresale el leitmotiv del vals un poco meno mosso. El perro negro de Duncan trata de morder a Paula; suena música atonal y, tras tres golpes de arco en el registro agudo -que de nuevo guardan similitud con la escena de la ducha de Psicosis- se escuchan glissandi descendentes y ascendentes en violines. Paula da muerte al perro con un abrecartas y suena el leitmotiv de las quintas en los violines en pianissimo, con una reducción del tempo, como sugiriendo los momentos de agonía de la bestia. Paula escapa de la casa en su coche y no puede evitar recordar su forcejeo con el canino, por lo que termina estrellándose. Una de las imágenes que aparecen en su mente es la de la fiesta y retorna la música diegética. La música atonal en la cuerda funde esta escena con la siguiente mediante visiones fugaces de Paula en las que el médico la analiza. El doctor le comenta que lo que ha causado el accidente es lo que sucede en su cabeza. Paula se mantiene firme a pesar de que la visión de quienes acuden a visitarla en el hospital está relacionada con una posible enfermedad y delirios.

Más tarde, Paula dice que quiere volver a ver a Myles, a pesar de lo que sabe de él. Cuando acaba de hablar suena el leitmotiv de un poco meno mosso. Hacia el minuto 92: 20, la joven decide acercarse a Myles por medio del ritual satánico. Se quita su camisón blanco frente a la vela negra, suenan campanas, de nuevo implicando la muerte. Tras hacer el ritual, aparece una figura misteriosa a la que ella, llena de excitación, llama maestro; música dodecafónica y leitmotiv de las quintas del Mephisto waltz en la cuerda al acabar el ritual. El sonido de los leitmotive hace que pueda identificarse a Duncan como el diablo en esta figura misteriosa, a pesar de que no se le ve el rostro en ningún momento.

Posteriormente, al minuto 97: 00 aparece Roxanne en la casa de Duncan vestida de blanco. Paula aparece allí y le dice que ha hecho un pacto con el diablo encomendado a él su alma y que él está de su parte ahora. Roxanne llama a su mayordomo, pero Paula la golpea con un objeto contundente en la cabeza y la deja inconsciente. Roxanne, vestida de blanco y agredida por Paula, parece representar ahora la inocencia. La joven convertida al satanismo la extrae sangre con una jeringuilla y se escucha el sonido de campanas afinadas en diferentes frecuencias, en una melodía acompañadas por las quintas en la cuerda. Las quintas se asocian, esta vez, al personaje de Paula quien, rápidamente, toma el molde de la cara de Roxanne para que su alma pueda emigrar a su cuerpo. En su desesperación, Paula se acerca al balcón mirando al cielo y pide ayuda a Myles. Suena el leitmotiv del vals en el piano junto con la cuerda y la flauta travesera. La melodía tiene pequeñas variaciones y el bajo efectúa una secuencia de notas atonal en ostinato. Después (minuto 101: 00), Paula aparece muerta en la bañera con el molde encima de la cara. 
Atonalismo y dodecafonismo en la gran pantalla: sus usos dentro del medio cinematográfico... Artículos

Un poco más tarde, Roxanne está fumando en casa de Duncan, mientras suena el leitmotiv de un poco meno mosso en el violoncelo, con un bajo atonal que funciona de forma independiente, lo que implica la apariencia del mal en el rostro de Roxanne con el alma de Paula en su cuerpo. Acto seguido, en el minunto 101: 56, Myles llega en coche y se escucha el leitmotiv de las quintas. Los dos leitmotive se reencuentran junto con los personajes principales. En la escena final se observa como el leitmotiv de un poco meno mosso se desarrolla y cambia; ahora es más elaborado. El leitmotiv evoluciona a música atonal antes del beso, hasta el momento en el que Duncan pregunta a Roxanne qué es lo tiene en las manos y ella le explica que ha cambiado su perfume. Duncan no parece darse cuenta de lo que ha sucedido y se besan. Reaparece entonces el ya mencionado leitmotiv, esta vez, en forma de arreglo tonal con variaciones sobre la melodía original en el piano. En esta escena la melodía del leitmotiv se convierte en un fraseo sobre la obra de Liszt y continúa con la música que compuso el autor. La imagen se paraliza y entra en el piano el leitmotiv de las quintas, también ceñido a la partitura, en cuanto a la forma en la que continúa el original. Aparece el color y el elemento asociados al satanismo; los colores de la imagen pasan, gradualmente, a un tono rojo y aparece fuego sobre la imagen, representando la descripción del infierno; limbo en el que los personajes principales acaban involucrados; por una vez más suenan las campanas.

\section{El uso de la música en The Mephisto Waltz (1971)}

En esta película encontramos varios leitmotive, pero nos centraremos en los dos más recurrentes: el primero lo forman las quintas superpuestas con las que da inicio el Mephisto waltz, que se escucha junto a las cuerdas en todas las apariciones, excepto en la escena en la que Duncan toca la obra al piano. Sobre este pasaje, las quintas superpuestas generan varias disonancias que en la Banda Sonora están relacionadas con Satán. El segundo leitmotiv es un pasaje concreto del vals en el que el cromatismo en la melodía lírica efectuada en el piano suena, también, en la cuerda. En la partitura original de Liszt es un poco meno mosso. Estos dos leitmotive sufren una evolución en sus sucesivas apariciones a lo largo del filme y se escuchan -especialmente este último- acompañados por la música dodecafónica y los ruidos que contiene la Banda Sonora, los cuales contribuyen a condicionar aspectos como el miedo, lo oscuro y las cavilaciones de Paula sobre los sucesivos crímenes como parte del pacto satánico. Goldsmith decide introducir el dodecafonismo en escenas de oscuridad y misterio.

Además, una gran parte del argumento de la película queda reducido a Paula, una mujer que acaba sacando su lado más oscuro para acercarse a quien ama. Roxanne y Paula son dos mujeres que concentran gran parte de la relación de este filme con el expresionismo literario y compositivo. Se corresponde con el cliché de la música de la Escuela de 
Viena en el cine. A continuación, mostramos una lista de los dos empleos de la composición musical de la Escuela de Viena y las interacciones con la obra romántica para piano y otros elementos sonoros en The Mephisto waltz (1971).

Por un lado, la música dodecafónica se utiliza para ambientar escenas oscuras relacionadas con el ritual satánico. Es decir, implica la maldad, en figuras como el perro negro. Además, se emplea para la narración de momentos de misterio y sensación de desconcierto. Resulta, entonces, un recurso para ambientar las reflexiones de Paula sobre los asesinatos y el pacto satánico. Por otro lado, el empleo de música atonal se presenta en los momentos de impresión o sorpresa, o bien cuando un personaje lee los textos del ritual satánico. También, la música atonal se escucha de fondo en los diálogos sobre los asesinatos y el presunto ritual satánico por parte de los personajes inocentes o "buenos" (Paula y Bill). No aparecen elementos musicales relacionados con el Mephisto waltz: la inocencia o bondad está relacionada con la no utilización de vals. El atonalismo se usa como referencia a conversaciones sobre cuestiones negativas

Asimismo, se emplea de música atonal y tonal como símbolo del amor carnal entre figuras malignas como el caso Duncan y Roxanne en el sueño de Paula, o bien en la escena de Duncan y Paula tras la conversión de la última al satanismo. Aparecen las quintas y el leitmotiv del pasaje un poco meno mosso justificados junto al atonalismo, porque implican un amor en el que interviene Satán. También se utiliza en eventos sociales de normalidad y presencia de la figura maligna, como el entierro de Duncan. Así como en referencia a Paula junto al cuerpo de Roxanne (el bajo atonal parece adquirir cierta independencia con respecto al motivo del Mephisto waltz, por lo que denota una dualidad de caracterizaciones).

En cuanto al Mephisto waltz No.1, los motivos de la obra en el piano ayudan a reconocer la figura de Duncan. A la vez, las quintas superpuestas de los violines ayudan a reconocer la figura del diablo en Duncan. En algunas ocasiones, también implican la huella de muerte que deja su pacto. Mientras que los ruidos sugieren presencias malignas y el mundo de los muertos. Finalmente, los glissandi se emplean, en ocasiones, en el cine de terror para subrayar escenas de miedo u horror. Además del misterio, el miedo, la confusión y la sensación de desconcierto, uno de los usos del dodecafonismo en la película -como se ha visto- está enfocado a las implicaciones reflexivas del propio personaje de Paula, ya que la música aporta cierto énfasis en las conspiraciones de la joven sobre el pacto satánico de Duncan. A pesar de que pueda resultar innovador que la música acompañe el pensamiento de Paula, sus reflexiones circulan en torno a sucesos que le producen miedo. Un aspecto que se corresponde, claramente, con las influencias de Schönberg es la aparición de los sueños; se hace notar la presencia de los mensajes del subconsciente en relación con el 
Atonalismo y dodecafonismo en la gran pantalla: sus usos dentro del medio cinematográfico... Artículos

psicoanálisis. En las escenas en las que Paula tiene pesadillas se hace uso del atonalismo, el cual guarda cierta relación con la vida de Schönberg, quien tuvo una cierta influencia de las teorías de Freud en su obra.

\section{Discusión}

La música erudita del siglo XX es un recurso creativo surgido de necesidades comunicativas que, ha constituido históricamente una forma de comunicación, sin embargo, el diálogo con el público se resintió entre finales del siglo XIX y principios del siglo XX. En nuestro trabajo hemos trabajado los usos de las estrategias compositivas de la Escuela de Viena, en el cine de la segunda mitad del siglo XX, al plantear la adaptación de dichas estrategias en la música de cine. Hemos estudiado la música en el cine, por la valoración de la misma dentro y fuera del medio cinematográfico, a la vez que sintetizamos las reflexiones de compositores, directores y estudiosos sobre la relevancia del aspecto musical del cine. Esta recopilación ha aportado información sobre la función de la música, no solo en el filme, sino como parte del proceso de montaje del mismo, lo cual interviene en el resultado final del producto y en la importancia que se le atribuye a la música en la elaboración del largometraje. Asimismo, hemos estudiado el distanciamiento entre los artistas y el público dentro de la música de vanguardia de la primera mitad del siglo XX, al analizar los modos de uso de la composición atonal y dodecafónica en el cine.

Las referencias y los contenidos audiovisuales que hemos analizado han contribuido a ofrecer nuevas visiones sobre la investigación del uso de la música en cine. Hemos aportado una pequeña revisión de la reutilización de la estética del atonalismo y la técnica dodecafónica en las producciones cinematográficas. De la misma forma, hemos hecho una lectura sobre la integración del cliché en el cine de género de terror o suspenso, como un factor de reiteración en el filme, además de constituir un elemento generador de nuevas formas de comprensión de las implicaciones musicales en el cine. Por otro lado, no dejan de introducirse en el medio, a modo de aprendizaje para el público, ya que la evolución de los lenguajes compositivos de la Escuela de Viena en el cine es, tal y como sucede en todo lo referente al aprendizaje humano, una cuestión dependiente de la reiteración. También, han podido esbozarse las consecuencias que surgen con el uso de la música atonal y dodecafónica en el cine, como término intermedio entre los usos de la música autónoma y la música programática.

El estudio de la ruptura comunicativa generada entre compositor y público ha sido importante para comparar los efectos que genera la música de la Escuela de Viena tanto en el formato de concierto como en el de largometraje. Puede comprobarse que el conocimiento de la música del siglo XX por parte de las masas ha sido posible, en gran parte, 
gracias a su presencia en los medios de comunicación. El desfase temporal entre los músicos de la Escuela de Viena y la presencia de las estrategias compositivas derivadas de la misma en el cine de la segunda mitad de siglo generó en el público un margen de desconocimiento que permitió redefinir y adaptar los significados estéticos de la música atonal y dodecafónica al cine. La ruptura comunicativa y el desfase temporal permitieron la inserción de la música atonal y dodecafónica como clichés de terror y suspenso, generándose un lenguaje audiovisual nuevo. El cliché de la música atonal y dodecafónica tiene una funcionalidad clara encaminada a la comprensión de sensaciones, sentimientos, ambientes o estados psicológicos. Otro de sus principales usos es resaltar situaciones, por lo general, de cierta tensión. Sus resultados son, por un lado, enriquecedores, ya que aporta nuevos componentes significativos dentro del filme y da ritmo a la ficción. Del mismo modo, crea sensación de reiteración y hace que la trama resulte ciertamente predecible. El análisis ha servido para dejar constancia de las principales ideas de nuestro planteamiento teórico, al mostrar los usos de la música atonal y dodecafónica, la estandarización de la disonancia como refuerzo de las tensiones en momentos de suspenso, terror y el cliché como elemento funcional integrado en el aspecto narrativo del filme.

\section{Referencias}

Adorno, T. \& Esler, H. (2005). El cine y la música. Madrid: Fundamentos.

Alcalde, J. (2007a). Pautas para el estudio de los orígenes de la música cinematográfica. Área abierta, (16), 1-9.

Alcalde, J. (2007b). Música y comunicación: puntos de encuentro básicos. Madrid: Fraqua.

Arcos (de), M. (2006) El experimentalismo en la música cinematográfica. Madrid: Fundación el monte.

Chion, M. (1997). La música en el cine. Barcelona: Paidós.

Laborada, J. (2004). La música moderna y contemporánea a través de los escritos de sus protagonistas. Sevilla: Editorial Doble J.

Lack, R. (1999). La música en el cine. Madrid: Cátedra D.L.

Marco, T. (2002). Pensamiento musical y siglo XX. Madrid: Fundación Autor.

Martin, Q. (productor). Wendkos, P. (director). (1971). The Mephisto waltz. [Película]. Estado Unidos: Quinn Martin Productions.

Mouëllic, G. (2011). La música en el cine. Barcelona: Paidós.

Roman, A. (2008). El lenguaje musivisual. Madrid: Visión libros. 